\title{
CORRECTION
}

\section{Correction to: Cortical Spreading Depolarizations in a Mouse Model of Subarachnoid Hemorrhage}

James H. Lai ${ }^{1,2}$, Tao Qin ${ }^{1}$, Sava Sakadžić ${ }^{3}$, Cenk Ayata ${ }^{1,4}$ and David Y. Chung ${ }^{1,2^{*}}$ (D)

(C) 2022 Springer Science+Business Media, LLC, part of Springer Nature and Neurocritical Care Society

\section{Correction to: \\ Neurocrit Care \\ https://doi.org/10.1007/s12028-021-01397-9}

This article was updated to correct errors introduced during the production process. Correction was made to change $\mathrm{ml}$ to $\mu \mathrm{l}$ in the abstract and Methods section.

\section{Author details}

${ }^{1}$ Neurovascular Research Unit, Department of Radiology, Massachusetts General Hospital, Harvard Medical School, 149 13th St, Charlestown, MA 02129, USA. ${ }^{2}$ Division of Neurocritical Care, Department of Neurology, Massachusetts General Hospital, Harvard Medical School, Boston, MA 02114, USA. ${ }^{3}$ Athinoula A. Martinos Center for Biomedical Imaging, Department of Radiology,
Massachusetts General Hospital, Charlestown, MA, USA. ${ }^{4}$ Stroke Service, Department of Neurology, Massachusetts General Hospital, Harvard Medical School, Boston, MA, USA.

\section{Publisher's Note}

Springer Nature remains neutral with regard to jurisdictional claims in published maps and institutional affiliations.

Published: 18 January 2022

Full list of author information is available at the end of the article 